\title{
Experimental Study of an Evaporator Heat Exchanger for a Rankine Cycle Vehicle Waste Heat Recovery System
}

\author{
H. Santos, N. Pires, D. Caseiro, J. Morgado, J. F. Pereira, and N. Martinho
}

\begin{abstract}
This article presents a Rankine cycle (RC) system as an additional power generation process, which uses the waste heat of a vehicle equipped with an internal combustion engine (ICE). A brief review of different heat recovery technologies leads to the identification of the $\mathrm{RC}$ system as a favorable solution for vehicle applications. The paper focuses on the performance evaluation of the evaporator heat exchanger (HEX) that is suitable for ICE waste heat recovery. The HEX performance depends on several parameters such as its structure, heat transfer area and temperature difference between hot gas and the RC working fluid. The investigated HEX is a cross-flow heat exchanger, simple and robust, with the working fluid circulating inside the tubes. A test bench that includes the vehicle and the RC system that uses water as working fluid, has been built in order to measure the HEX performance. A detailed description of the experimental setup is presented. Finally, test bench measurements of the applied vehicle coupled with the HEX fitted on the RC system were carried out.
\end{abstract}

Index Terms-Waste heat recovery, Rankine cycle, evaporator heat exchanger, experimental results.

\section{INTRODUCTION}

During the last decade the automobile industry has made great progress in improving ICE efficiency. The research activities have mainly focused on the optimization of fuel/air mixture preparation and the combustion process. Nevertheless, today's ICE efficiency is reaching its technical limit and will not be sufficient enough to meet future fuel economy targets without additional measures. Nowadays, regulations are focused on $\mathrm{CO}_{2}$ emissions, which require increasing the efficiency of the ICE or moving to more costly vehicle propulsion systems (e.g., hybrid drivetrains). To increase the ICE thermal efficiency and to reduce $\mathrm{CO}_{2}$ emissions, different waste heat recovery (WHR) techniques were recently proposed [1]-[9].

Among the existing WHR techniques, the most relevant are the electrical turbo-compounding (ETC), the mechanical turbo-compounding (MTC), the thermo-electric generator (TEG) and the Rankine cycle (RC) or organic Rankine cycle (ORC) [3]. In what concerns to the RC, recent studies [5], [10] have supported that the $\mathrm{RC}$ is a high potential technique for automotive applications. The $\mathrm{RC}$ is based on the steam generation in a secondary circuit that represents an indirect method of WHR. This technique has advantages compared to the so-called direct WHR techniques (e.g., ETC and MTC)

Manuscript received March 3, 2015; revised September 9, 2015.

The authors are with the School of Technology and Management, Polytechnic Institute of Leiria, Leiria, Morro do Lena - Alto Vieiro Apt. 4163, 2411-901 Leiria, Portugal (e-mail: \{helder.santos, nuno.pires, david.caseiro, joel.morgado, fonseca.pereira, nuno.martinho\}@ipleiria.pt). that uses a power turbine fitted to the vehicle exhaust, which has a much higher impact on the ICE pumping losses.

The differences in the thermal processes (RC and TEG) in heat utilization are mainly caused by the ability to use the temperature difference. The heat transfer by gas-to-material of a TEG device makes the heat utilization for a given heat exchanger surface more difficult in comparison to the evaporation procedure of a RC system. Furthermore, current efficiencies of TEG devices are lower than those of a Rankine cycle system, but future material development could offer the chance to efficiently generate electrical power directly on-board. To summarize the RC system can be identified as a favorable approach for the recuperation of ICE waste heat.

The two primary sources of waste heat from an ICE are the ICE exhaust (medium-grade) and ICE coolant (low-grade). Other options for WHR include the relatively smaller amounts of heat available from an exhaust gas recirculation (EGR) cooler and charge air cooler (CAC) [7]. Despite the similar energy amount available on primary sources, exhaust and coolant, the higher temperature of the ICE exhaust makes it thermodynamically more attractive for heat to power conversion.

This work is dedicated to the design and implementation of a RC-WHR system. This system requires the introduction of a HEX in the vehicle exhaust line. The work is divided into two main parts: i) the description of the RC system test bench; ii) the study of the HEX performance.

\section{SYSTEM LAYOUT}

Based on a RC system various configurations can be identified to recovery the ICE waste heat. These configurations differ in the utilization of the heat source (exhaust gas, EGR and/or coolant system). In this paper, a simple layout with one fluid loop for gathering the exhaust gas waste heat was selected aiming for future implementation in a passenger vehicle. This layout was chosen to minimize system complexity, weight and costs in detriment of maximizing the power obtained.

Fig. 1 depicts the RC-WHR system layout. The RC system is composed by four main components: a pump, an evaporator heat exchanger (HEX), an expander and a condenser. The WF circuit is represented in the Fig. 1 with a blue line. The pump supplies the working fluid (WF) to the HEX, where the WF is heated and vaporized gathering heat from the exhaust gases (EG). The WF leaves the HEX in superheated state. The high enthalpy vapor is then expanded in the expander (usually a turbine), which is coupled to a generator that deliveries the RC power output. After the expander, the WF enters the condenser where it condensates. Completing the WF circuit, the WF gets back to the reservoir, 
which is at the atmospheric pressure.

In addition there is a security WF circuit, represented on Fig. 1 in orange. The security WF circuit uses solenoid valves that were controlled by Labview ${ }^{\circledR}$ software.

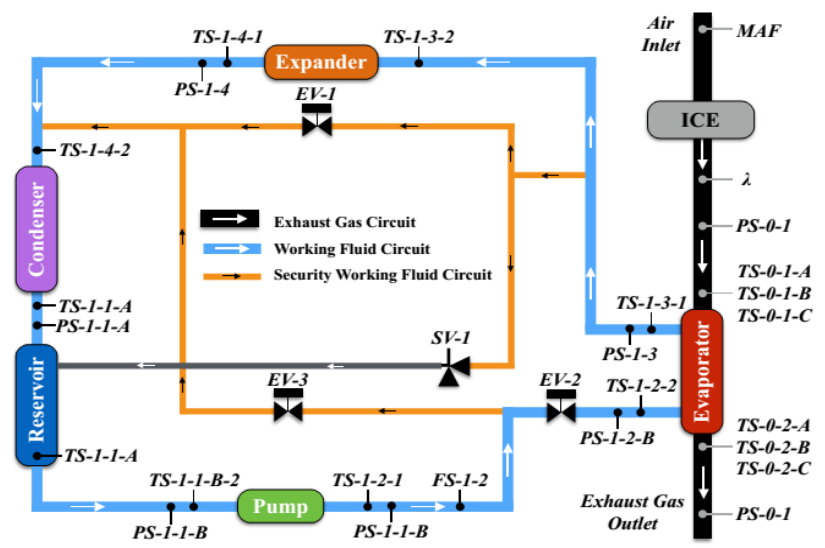

Fig. 1. RC-WHR system layout. The black line represents the exhaust gas circuit, the blue line represents the working fluid circuit and the orange line represents the security circuit.

For data acquisition and control a dedicated software (Labview ${ }^{\circledR}$ ) was used. The computer uses two data acquisition boards from National Instruments: PCI-6221 e PCI-6225. These acquisition boards are connected to signal condition boards with thermocouple cold junction compensation (CJC). A signal condition board CB-68LP was connected to the data acquisition board PCI-6221 and two signal condition boards SCC-68 were connected to PCI-6225. The developed software allows using data from the sensors to manage the actuators, display the data in different diagrams and graphics and save it for posterior analysis. Several sensors and actuators were installed to get the required data and to have an appropriate control.

\section{A. Vehicle Sensors}

The vehicle used in the experiments was equipped with a programmable engine control unit (ECU) - Motec M4 allowing us to access the data of several sensors. Table I shows the data saved from the vehicle and chassis dynamometer test bench.

TABLE I: VEHICLE AND CHASSIS DYNAMOMETER DATA

\begin{tabular}{lcl}
\hline \hline Variable name & Units & Description \\
\hline MAF & $\mathrm{kg} / \mathrm{s}$ & Engine intake mass air flow rate \\
Lambda & - & Oxygen sensor value \\
Maha speed & $\mathrm{km} / \mathrm{h}$ & Vehicle speed during the tests \\
Mahaft & $\mathrm{N}$ & Vehicle traction force during the tests \\
Wheel power & $\mathrm{kW}$ & Vehicle wheel power during the tests \\
\hline \hline
\end{tabular}

\section{B. Pressure Sensors}

On the exhaust gas (EG) circuit it was installed two pressure sensors (before and after the HEX). On the WF circuit it was installed six pressure sensors. Table II summarize the data saved from the pressure sensors.

\section{Thermocouples}

A total of six thermocouples were installed on the EG circuit and nine thermocouples were installed along the WF circui. Table III summarize the data obtained from the thermocouples.
TABLE II: PRESSURE SENSORS DATA

\begin{tabular}{lccl}
\hline \hline Variable name & Units & Fluid & Location \\
\hline$P S-0-1$ & $\mathrm{kPa}$ & $\mathrm{EG}$ & Before evaporator \\
$P S-0-2$ & $\mathrm{kPa}$ & $\mathrm{EG}$ & After evaporator \\
$P S-1-1-A$ & $\mathrm{kPa}$ & $\mathrm{WF}$ & Before reservoir \\
$P S-1-1-B$ & $\mathrm{kPa}$ & $\mathrm{WF}$ & Before pump \\
$P S-1-2-A$ & $\mathrm{kPa}$ & $\mathrm{WF}$ & After pump \\
$P S-1-2-B$ & $\mathrm{kPa}$ & $\mathrm{WF}$ & Before evaporator \\
$P S-1-3$ & $\mathrm{kPa}$ & $\mathrm{WF}$ & After evaporator \\
$P S-1-4$ & $\mathrm{kPa}$ & $\mathrm{WF}$ & After expander \\
\hline \hline
\end{tabular}

TABLE III: THERMOCOUPLES DATA

\begin{tabular}{lccl}
\hline \hline Variable name & Units & Fluid & Location \\
\hline$T S-0-1-A$ & $\mathrm{~K}$ & EG & Before evaporator \\
$T S-0-1-B$ & $\mathrm{~K}$ & EG & Before evaporator \\
$T S-0-1-C$ & $\mathrm{~K}$ & EG & Before evaporator \\
$T S-0-2-A$ & $\mathrm{~K}$ & EG & After evaporator \\
$T S-0-2-B$ & $\mathrm{~K}$ & EG & After evaporator \\
$T S-0-2-C$ & $\mathrm{~K}$ & EG & After evaporator \\
$T S-1-1-A$ & $\mathrm{~K}$ & $\mathrm{WF}$ & After condenser \\
$T S-1-1-B-1$ & $\mathrm{~K}$ & $\mathrm{WF}$ & Inside of reservoir \\
$T S-1-1-B-2$ & $\mathrm{~K}$ & $\mathrm{WF}$ & Before pump \\
$T S-1-2-1$ & $\mathrm{~K}$ & $\mathrm{WF}$ & After pump \\
$T S-1-2-2$ & $\mathrm{~K}$ & $\mathrm{WF}$ & Before evaporator \\
$T S-1-3-1$ & $\mathrm{~K}$ & $\mathrm{WF}$ & After evaporator \\
$T S-1-3-2$ & $\mathrm{~K}$ & $\mathrm{WF}$ & Before expander \\
$T S-1-4-1$ & $\mathrm{~K}$ & $\mathrm{WF}$ & After expander \\
$T S-1-4-2$ & $\mathrm{~K}$ & $\mathrm{WF}$ & Before condenser \\
\hline \hline
\end{tabular}

\section{WF Flowmeter and Pump Control}

The WF flowmeter sensor (FS-1-2, see Fig. 1) is very important because it allows the pump to be controlled using a PID control. We have control over the WF mass flow rate, by controlling the pump supply voltage. This allows controlling the WF superheating temperature after the HEX.

\section{E. Valves}

The valves allow control over the route of the WF circuit and are related to the RC system safety. A total of five valves were used:

- EV-1 - controls the by-pass of expander - normally the valve is closed;

- EV-2 - controls the entrance to the evaporator normally the valve is open;

- EV-3 - controls the by-pass of evaporator and expander - normally the valve is closed;

- SV-1 - opens in case of overpressure (above $800 \mathrm{kPa}$ ) — normally the valve is closed.

\section{VEHICLE TEST CONDITIONS}

The exhaust gas is provided by a Ford Sierra with a 2.01 gasoline ICE. Table IV presents the ICE main characteristics.

In order to study the HEX performance under practical operating conditions, a matrix of six vehicle test conditions (VTC) was defined. For each VTC the following test procedure was applied: startup of the WF circuit; startup of the EG circuit; heating phase; testing phase; cooling/post-testing phase.

In this paper, for brevity we analyze the experimental data gathered for the VTC2 and the VTC4. Table V shows the VTC investigated and the respective engine speed, mean effective pressure (MEP), EG temperature at HEX inlet and EG mass flow rate. 


\begin{tabular}{ll}
\multicolumn{2}{c}{ TABLE IV: ICE CHARACTERISTICS } \\
\hline \hline ICE & Ford 2.0 OHC \\
\hline Total Valves & 8 \\
Cylinders & 4 Inline \\
Displacement & $1993 \mathrm{~cm}^{3}$ \\
Compression Ratio & $9.44: 1$ \\
Max Power @ rpm & $81 \mathrm{~kW} @ 5500 \mathrm{rpm}$ \\
Max Torque @ rpm & $164 \mathrm{Nm} @ 3500 \mathrm{rpm}$ \\
Bore / Stroke & $90.3 \mathrm{~mm} / 76.95 \mathrm{~mm}$ \\
Fuel & Gasoline \\
\hline \hline
\end{tabular}

TABLE V: VEHICLE TEST CONDITIONS (VTC)

\begin{tabular}{lcccc}
\hline \hline Name & Engine Speed $(\mathrm{rpm})$ & $\begin{array}{c}M E P \\
(\mathrm{kPa})\end{array}$ & $\begin{array}{c}T_{E G}, \text { in } \\
(\mathrm{K})\end{array}$ & $\begin{array}{c}m_{E G} \\
(\mathrm{~g} / \mathrm{s})\end{array}$ \\
\hline VTC 2 & 3000 & 0 & 861.45 & 14.75 \\
VTC 4 & 3000 & 400 & 912.10 & 27.51 \\
\hline \hline
\end{tabular}

\section{RESULTS AND DISCUSSION}

The working fluid (WF) gets the heat provided by exhaust gases (EG). The component where this exchange is made is called evaporator heat exchanger (HEX). Various heat exchanger designs and configurations were analyzed in order to compare their efficiency. The heat exchangers were designed considering specific pressure drops limits on both exhaust gas and working fluid side.

In this paper, the investigated HEX, has 2.7 liter volume, design based on a cross-flow arrangement, simple and robust. The working fluid flows inside the tubes while the exhaust gas passes across the tube bank, as shown in Fig. 2.

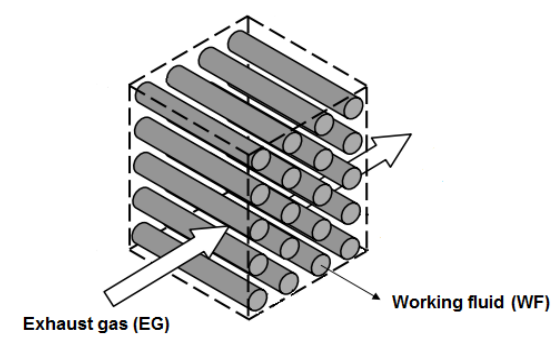

Fig. 2. HEX with cross-flow arrangement, the WF flows inside the tubes and EG passes across the tube bank, adapted from [11].

By changing the tube diameter, length and arrangement, great flexibility can be found in a cross-flow HEX. The cross-flow HEX was tested with the tube bank in the horizontal orientation, WF flows in the horizontal (as shown in Fig. 2) and in the vertical orientation, WF flows in the vertical.

\section{A. Experimental Results}

\begin{tabular}{lcccccc}
\multicolumn{7}{c}{ TABLE VI: ExHAUST GAS DATA FOR THE VTC 2 } \\
\hline \hline \multirow{2}{*}{ Condition } & Test & $\begin{array}{c}T_{E G}, \text { in } \\
(\mathrm{K})\end{array}$ & $\begin{array}{c}T_{E G}, \text { out } \\
(\mathrm{K})\end{array}$ & $\begin{array}{c}m_{E G} \\
(\mathrm{~g} / \mathrm{s})\end{array}$ & $\begin{array}{c}P_{E G}, \text { in } \\
(\mathrm{kPa})\end{array}$ & $\begin{array}{c}P_{E G} \text {, out } \\
(\mathrm{kPa})\end{array}$ \\
\hline \multirow{3}{*}{ Horizontal } & 1 & 860.8 & 551.8 & 15.02 & 102.73 & 100.03 \\
& 2 & 866.0 & 556.0 & 14.84 & 103.76 & 101.01 \\
& 3 & 874.5 & 559.1 & 15.00 & 103.63 & 100.77 \\
\hline \multirow{3}{*}{ Vertical } & 1 & 841.2 & 410.6 & 14.47 & 103.12 & 99.56 \\
& 2 & 864.7 & 411.0 & 14.95 & 103.04 & 99.69 \\
& 3 & 861.5 & 412.4 & 14.81 & 102.96 & 99.83 \\
\hline \hline
\end{tabular}

The measurements presented in this paper constitute the first set of measurements collected on this test bench. For each HEX orientation (horizontal and vertical) 3 tests were made. Table VI presents the exhaust gas data obtained for the VTC 2.

Note that, $T_{E G \text {, in }}$ and $T_{E G \text {, out }}$ are the exhaust gas temperature measured at the inlet and outlet of the HEX, which are an average of TS-0-1(A, B, C) and TS-0-2(A, B, C), respectively. The $m_{E G}$ is the exhaust gas mass flow rate. The $P_{E G \text {, in }}$ and $P_{E G \text {,out }}$ is the exhaust gas absolute pressure measured at the inlet and outlet of the HEX, respectively. Table VI reveals that the $T_{E G \text {,out }}$ for the HEX vertical orientation is lower than for the HEX horizontal orientation. The experimental data allows to calculate the exhaust gas thermal power:

$$
\dot{Q_{E G}}=m_{E G} \times C_{p} \times\left(T_{E G \text {,in }}-T_{E G \text {,out }}\right)
$$

It is important to point out that with the HEX in the vertical orientation the exhaust gas thermal power is higher than for the horizontal orientation, this is due to the lower $T_{E G \text {, out }}$ (see Table VI). This allows us to conclude that the HEX works better with the tube bank in the vertical orientation.

Table VII summarizes the working fluid data gathered for the VTC 2.

\begin{tabular}{lccccc}
\multicolumn{5}{c}{ TABLE VII: WORKING FLUID DATA FOR THE VTC 2 } \\
\hline \hline \multirow{2}{*}{ Condition } & Test & $\begin{array}{c}T_{W F}, \text { in } \\
(\mathrm{K})\end{array}$ & $\begin{array}{c}T_{W F}, \text { out } \\
(\mathrm{K})\end{array}$ & $\begin{array}{c}m_{W F} \\
(\mathrm{~g} / \mathrm{s})\end{array}$ & $\begin{array}{c}P_{W F}, \text { in } \\
(\mathrm{kPa})\end{array}$ \\
\hline \multirow{3}{*}{ Horizontal } & 1 & 304.7 & 553.7 & 1.79 & 503.44 \\
& 2 & 301.3 & 559.4 & 1.78 & 521.03 \\
& 3 & 303.3 & 557.1 & 1.83 & 516.65 \\
\hline \multirow{3}{*}{ Vertical } & 1 & 301.0 & 594.5 & 2.23 & 519.50 \\
& 2 & 296.8 & 544.0 & 2.38 & 511.55 \\
& 3 & 298.1 & 554.0 & 2.32 & 519.01 \\
\hline \hline
\end{tabular}

In the Table VII the $T_{W F}$, in and $T_{W F \text {,out }}$ are the WF temperature at the HEX inlet and outlet, respectively. The $\dot{m}_{W F}$ is the working fluid mass flow rate and the $P_{W F}$, in is the working fluid pressure at the HEX inlet. It can be observed that the WF mass flow rate is higher for the vertical orientation than for the horizontal orientation. Note that, the vertical orientation allows higher exhaust gas thermal power and so that WF mass flow rate was increased to keep the similar WF temperature at the HEX outlet $\left(T_{W F}\right.$, out $)$.

TABLE VIII: EXHAUST GAS DATA FOR THE VTC 4

\begin{tabular}{lcccccc}
\hline \hline \multirow{2}{*}{ Condition } & Test & $\begin{array}{c}T_{E G} \text {, in } \\
(\mathrm{K})\end{array}$ & $\begin{array}{c}T_{E G}, \text { out } \\
(\mathrm{K})\end{array}$ & $\begin{array}{c}m_{E G} \\
(\mathrm{~g} / \mathrm{s})\end{array}$ & $\begin{array}{c}P_{E G}, \text { in } \\
(\mathrm{kPa})\end{array}$ & $\begin{array}{c}P_{E G} \text {, out } \\
(\mathrm{kPa})\end{array}$ \\
\hline \multirow{3}{*}{ Horizontal } & 1 & 920.4 & 605.4 & 28.83 & 104.23 & 101.60 \\
& 2 & 908.2 & 582.3 & 27.16 & 104.71 & 102.22 \\
& 3 & 909.6 & 586.9 & 27.13 & 104.54 & 102.16 \\
\hline \multirow{3}{*}{ Vertical } & 1 & 909.8 & 446.9 & 26.90 & 104.24 & 101.45 \\
& 2 & 913.4 & 449.9 & 27.69 & 104.11 & 101.40 \\
& 3 & 911.2 & 447.6 & 27.32 & 104.02 & 101.26 \\
\hline \hline
\end{tabular}

TABLE IX: WORKING FLUID DATA FOR THE VTC 4

\begin{tabular}{lccccc}
\hline \hline Condition & Test & $\begin{array}{c}T_{W F}, \text { in } \\
(\mathrm{K})\end{array}$ & $\begin{array}{c}T_{W F}, \text { out } \\
(\mathrm{K})\end{array}$ & $\begin{array}{c}m_{W F} \\
(\mathrm{~g} / \mathrm{s})\end{array}$ & $\begin{array}{c}P_{W F}, \text { in } \\
(\mathrm{kPa})\end{array}$ \\
\hline \multirow{3}{*}{ Horizontal } & 1 & 308.5 & 602.6 & 3.28 & 513.71 \\
& 2 & 303.8 & 612.0 & 3.12 & 501.34 \\
& 3 & 306.4 & 622.1 & 3.22 & 497.01 \\
\hline \multirow{3}{*}{ Vertical } & 1 & 300.4 & 560.4 & 4.35 & 488.20 \\
& 2 & 299.4 & 562.7 & 4.57 & 482.57 \\
& 3 & 301.0 & 553.3 & 4.49 & 498.83 \\
\hline \hline
\end{tabular}


Table VIII presents the exhaust gas data obtained for the VTC 4 and Table IX presents the working fluid data obtained for the VTC 4.

As it was observed for the VTC 2, for the VTC 4 the $T_{E G \text {, out }}$ is lower for vertical orientation, which reveals that the performance of the HEX is higher when the tube bank works in the vertical orientation.

\section{B. HEX Efficiency}

The HEX efficiency was defined as follows:

$$
\eta_{, H E X}=\frac{\dot{m}_{E G} C_{p . \text { mean }}\left(T_{E G . \text { in }}-T_{E G, \text { out }}\right)}{\dot{m}_{E G} C_{p . \text { mean }}\left(T_{E G . \text { in }}-T_{a m b}\right)}
$$

The HEX efficiency corresponds to the ratio between the exhaust gas thermal power (measured experimentally) and the maximum thermal power that can be removed, which corresponds to $T_{E G \text {, out }}=T_{a m b}$.

Fig. 3 and Fig. 4 show the HEX efficiency for the VTC 2 and VTC4, respectively.

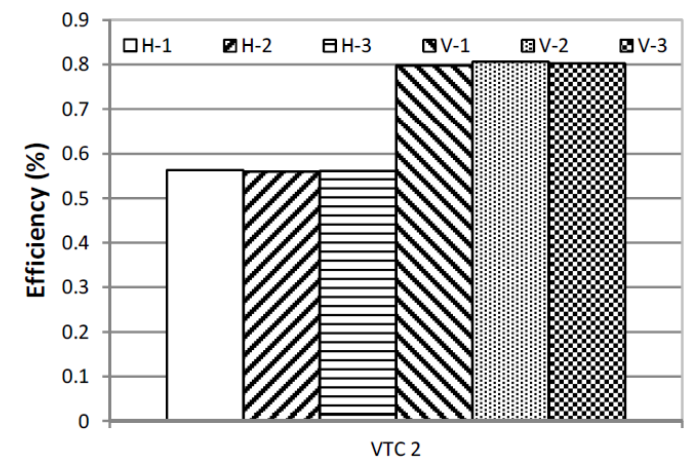

Fig. 3. HEX efficiency for the VTC 2.

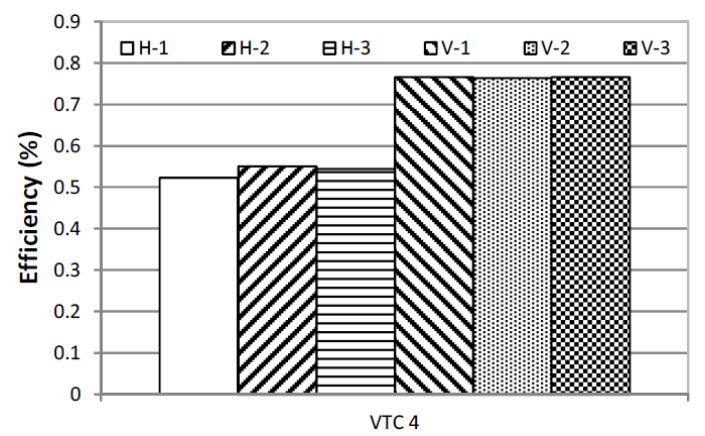

Fig. 4. HEX efficiency for the VTC 4.

As expected, Fig. 3 and Fig. 4 demonstrate that the HEX efficiency is higher for the vertical orientation of the tube bank than for the horizontal orientation. Specifically, for the VTC 2 the HEX average efficiency is $56.2 \%$ for the horizontal orientation and $80.3 \%$ for the vertical orientation. For the VTC 4 the HEX average efficiency is $53.9 \%$ for the horizontal orientation and $76.5 \%$ for the vertical orientation.

The specific thermal power, which corresponds to the ratio of the working fluid thermal power to the HEX volume, must be maximized. The experimental data allows to calculate the working fluid thermal power:

$$
Q_{W F}^{\cdot}=m_{W F} \times\left(h_{W F \text {,in }}-h_{W F \text {,out }}\right)
$$

The average specific thermal power data gathered for the cross flow HEX prototype were for the VTC2:
- $\dot{Q}_{W F} / \mathrm{V}_{H E X}=1.93 \mathrm{~kW} / \mathrm{l}$, for the horizontal orientation;

- $\dot{Q}_{W F} / \mathrm{V}_{H E X}=2.51 \mathrm{~kW} / \mathrm{l}$, for the vertical orientation. And, for the VTC 4:

- $\dot{Q}_{W F} / \mathrm{V}_{H E X}=3.57 \mathrm{~kW} / \mathrm{l}$, for the horizontal orientation;

- $\dot{Q}_{W F} / \mathrm{V}_{H E X}=4.84 \mathrm{~kW} / \mathrm{l}$, for the vertical orientation.

\section{CONCLUSION}

The Rankine cycle (RC) system was identified as a favorable approach for waste heat recovery in automotive vehicles.

A feasible RC system layout for the recovery of ICE exhaust waste heat using water as working fluid was presented. The Rankine cycle system has been designed and tested for a waste heat recovery application dedicated to a gasoline passenger car. Some experimental results for the evaporator heat exchanger have been presented.

The experimental data reveals that the cross-flow evaporator (HEX) has higher efficiency when the tube bank is vertical aligned.

The cross-flow type HEX design is very compact and robust, which allows to support the withstand pressure with boiling heat transfer on the working fluid side. Furthermore, the usage of corrugated tubes provides the additional advantage of reducing material stresses, especially under demands of temperature cycle operation due to the elasticity of the tubes.

To further increase the cross-flow HEX compactness, in a future research finned surfaces will be employed on the exhaust gases side to increase the heat transfer area.

\section{ACKNOWLEDGMENT}

The authors would like to thank André Almeida, Ruben Santos, Diogo Duro, Carlos Ferreira and Adrian Folgueira who contributed in conducting the experimental work presented here. This work was supported by the project: "Development of heat exchangers for application in thermal energy recovery systems in automotive vehicles", a research project of the School of Technology and Management, Polytechnic Institute of Leiria, Leiria, Portugal and BorgWarner Emissions System, S.L., Vigo, Spain.

\section{REFERENCES}

[1] C. Yu and K. T. Chau, "Thermoelectric automotive waste heat recovery using maximum power point tracking," Energy Conversion and Management, vol. 50, pp. 1506-1512, 2009.

[2] E. H. Wang, H. G. Zhang, B. Y. Fan, M. G. Ouyang, Y. Zhao, and Q. H. $\mathrm{Mu}$, "Study of working fluid selection of organic Rankine cycle (ORC) for engine waste heat recovery," Energy, vol. 36, pp. 3406-3418, 2011.

[3] I. Vaja and A. Gambarotta, "Internal combustion engine (ICE) bottoming with Organic Rankine Cycles (ORCs)," Energy, vol. 36, pp. 1084-1093, 2010.

[4] K. K. Srinivasan, P. J. Mago, and S. R. Krishnan, "Analysis of exhaust waste heat recovery from a dual fuel low temperature combustion engine using an organic Rankine cycle," Energy, vol. 35, pp. 2387-2399, 2010.

[5] N. Yamada and M. N. A. Mohamed, "Efficiency of hydrogen internal combustion engine combined with open steam rankine cycle recovering water and waste heat," International Journal of Hydrogen Energy, vol. 35, pp. 1430-1442, 2010.

[6] E. W. Miller, T. J. Hendricks, and R. B. Peterson, "Modeling energy recovery using thermoelectric conversion integrated with an organic Rankine bottoming cycle," Journal of Electronic Materials, vol. 38, pp. 1206-1213, 2009. 
[7] C. Sprouse and C. Depcik, "Review of organic rankine cycles for internal combustion engine exhaust waste heat recovery," Applied Thermal Engineering, vol. 51, pp. 711-722, 2013.

[8] K. Tang and H. Zhang, "Performance analysis of the Organic Rankine Cycle (ORC) system under engine various operating conditions," Journal of Clean Energy Technologies, vol. 3, no. 5, 2015.

[9] M. He, X. Zhang, K. Zeng, and K. Gao, "A combined thermodynamic cycle used for waste heat recovery of internal combustion engine," Energy, vol. 36, pp. 6821-6829, 2011.

[10] A. Domingues, H. Santos, and M. Costa, "Analysis of vehicle exhaust waste heat recovery potential using a Rankine cycle," Energy, vol. 49, pp. 71-85, 2013.

[11] W. A. Khan, J. R. Culham, and M. M. Yovanovich, "Optimal design of tube banks in crossflow using entropy generation minimization method," Journal of Thermophysics and Heat Transfer, vol. 21, no. 2, 2007.

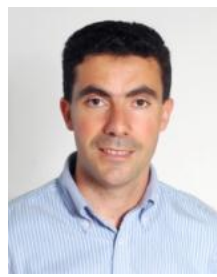

H. Santos was born in Portugal on July 30, 1976. He got his mechanical engineering bachelor's degree at University of Coimbra, Portugal, in 2000 and his master degree and $\mathrm{PhD}$ degree from Lisbon Technical University, Portugal, in 2006 and 2010 respectively. From 2000 to present, he has been a professor at the Mechanical Engineering Department, School of Technology and Management, Polytechnic Institute of Leiria, Portugal. His research interests are vehicle exhaust gas after treatment systems and waste heat recovery in automotive vehicles.

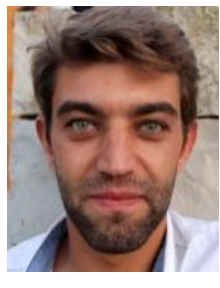

N. Pires was born in Portugal on January 3, 1981. He got his mechanical engineering bachelor's degree at Institute Polytechnic of Leiria, Portugal, in 2006 and his master degree in automotive engineering at Institute Polytechnic of Leiria, in 2011. From 2004 to present, he develops functions as a technician in the Laboratory of Automotive Engineering at School of Technology and Management, of Polytechnic Institute of Leiria, Portugal. His research interests are engine exhaust gas emissions and fuel consumption and engine control in automotive vehicles.

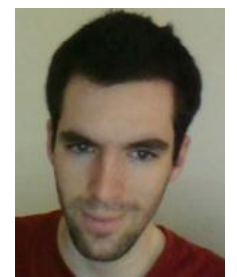

D. Caseiro was born in Portugal on May 29, 1990. He got his automotive engineering bachelor's degree and his master degree at Polytechnic Institute of Leiria, Portugal, in 2011 and 2013 respectively. Now he is a research student at the Polytechnic Institute of Leiria His research interests include waste heat recovery, Rankine cycle system for automotive vehicles and sensors.

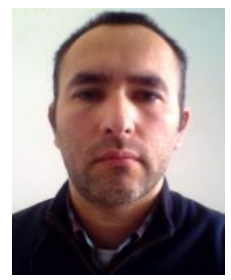

J. Morgado was born in Portugal on November 18 1976. He got his mechanical engineering bachelor's degree and his master degree at the University of Coimbra, Portugal, in 1999 and 2004 respectively. From 2004 to present, he is an assistant at the Mechanical Engineering Department, School of Technology and Management, Polytechnic Institute of Leiria, Portugal. His research interests are waste heat recovery in automotive vehicles.

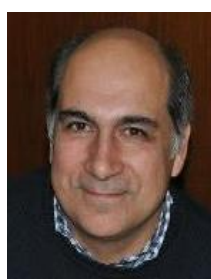

J. F. Pereira was born in Leiria, Portugal, in 1966. In 1991 he received the bachelor's degree in Naval Engineering, Mechanical Branch in Portuguese Navy Naval Academy. After 8 years of military career in the Portuguese navy, J. F. Pereira started his career as a professor at Polytechnic Institute of Leiria, Portugal, in the automotive engineering area. In 2005 and 2011, he received the M.Sc. and Ph.D. degrees in mechanical engineering from Lisbon Technical University, Portugal. His research interests are focused on engine intake systems and waste heat recovery in automotive engines.

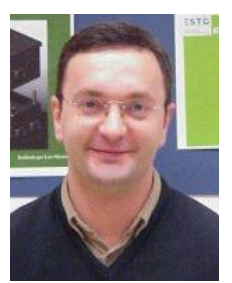

N. Martinho was born in Portugal on December 19 1970. He got his bachelor, master and PhD degrees in the area of mechanical engineering - aerodynamics, at Coimbra's University, Portugal, with the las presented in 2012. Since 1998, he is a professor at the Mechanical Engineering Department, School of Technology and Management, Polytechnic Institute of Leiria, Portugal. His research interests are numerical simulation of fluid flow (CFD), thermal comfort in automotive compartments and waste heat recovery in automotive vehicles. 